\title{
Determination of toxic phorbol esters in biofertilizer produced with Jatropha curcas seed cake
}

\author{
Vittaya Punsuvon $^{\mathrm{a}, \mathrm{b}, \mathrm{c}}$, Rayakorn Nokkaew ${ }^{\mathrm{b}}$, Sujinna Karnasuta ${ }^{\mathrm{d}, *}$ \\ a Department of Chemistry, Faculty of Science, Kasetsart University, Bangkok 10900 Thailand \\ b Centre of Excellence-Oil Palm, Kasetsart University, Bangkok 10900 Thailand \\ c Centre for Advanced Studies in Tropical Natural Resources, NRU-KU, Kasetsart University, \\ Bangkok 10900 Thailand \\ d College of Environment, Kasetsart University, Bangkok 10900 Thailand
}

*Corresponding author, e-mail: sujinna@gmail.com

Received 29 Jul 2011

Accepted 31 Mar 2012

\begin{abstract}
Seeds of Jatropha curcas contain oils, essential amino acids, and toxic phorbols that are found to be carcinogenic. Application of $J$. curcas seed cake for producing biofertilizer for growing sweet potato was studied in this work. The $J$. curcas seed cake, soil, and sweet potato were examined to determine the contamination of phorbol esters residue after the plant was treated with $J$. curcas seed cake fertilizer. Our study develops a technique to confirm the presence of phorbol esters residue by using liquid chromatography-tandem mass spectrometry with multiple reaction monitoring mode that detects the ionization of parent molecule with mass 711 to precursor and product ion with mass 311 and 293 , respectively. This technique is recommended to confirm phorbol esters residue. The results showed that both sweet potato and soil after harvesting did not have contamination with toxic phorbol esters.
\end{abstract}

KEYWORDS: residue, ionization, sweet potato, toxic substance

\section{INTRODUCTION}

Jatropha curcas is a drought-resistant plant which belongs to the Euphobiaceae family. It is widely cultivated in central and south America, south-east Asia, India, and Africa. Since it is a multipurpose tree, it has been promoted for planting in Thailand. It can be grown in low to high rainfall areas either in farms as a commercial crop or as a hedge to protect fields and prevent erosion. Its seeds contain a high amount of oil content approximately 50-60\% which is a good source of biodiesel fuel ${ }^{1}$. After extraction of oil, the $J$. curcas seed cake is rich in protein between 50-64\%. Except for lysine, all other essential amino acids in the cake have been reported to have higher concentrations than those referenced by the Food and Agriculture Organization. However, the $J$. curcas seed cake was found to be toxic to mice, rats, calves, sheep, goats, human, and chickens, and its use has been restricted. Some antinutritional components, such as saponin, phytate, trypsin inhibitor, glucosinolateds, amylase inhibitors, flavonoids, vitexin, isovitexin, and cyanogenic, as well as toxic irritant compounds, such as curcin, $\beta$-D-glycosides of sitosterol, and 12-deoxy16-hydroxy phorbol were reported in $J$. curcas seed cake. These phorbol esters (PEs) present at high levels in the cake have been identified as the main toxic agent. If these toxic agents can be removed, J. curcas seed cake could be used as a protein source for livestock feeds ${ }^{2}$.

The term PE is used today to describe a naturally occurring family of compounds widely distributed in plant species of the Euphobiaceae family. These compounds are esters of tigliane diterpenes. The fundamental substance, the alcohol moiety of this family compounds, is a tetracyclic diterpene (Fig. 1).

The hydroxylation of this fundamental substance in various positions and concentrations to various acid moieties by ester bonding characterize the large number of compounds termed PE which have the main chemical structure shown in Fig. 1.

The biological effect of this compound is tumour promotion and cell proliferation. The determination of $\mathrm{PE}$ content is usually analysed by high performance liquid chromatography with UV detector (HPLC$(\mathrm{UV})^{3}$. There is little literature on PE confirmation. The first work identifying PE in J. curcas oil by ESIMS/MS found that the parent ion of PE has molecular mass 711 and its daughter ions have mass 693, 383, 311 , and 293, respectively ${ }^{4}$.

The second method was liquid chromatographytandem mass spectrometry (LC-MS/MS) technique to 


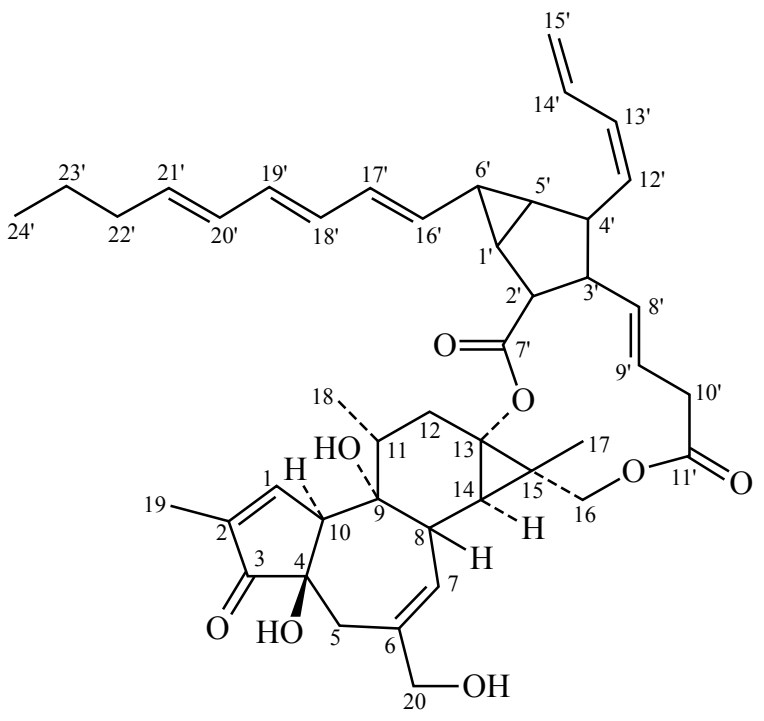

Fig. 1 Chemical structure of the main phorbol esters and tigliane.

detect tumour-promoting diterpene esters of tigliane within plant extracts ${ }^{5}$. The experiment employed fractionation on a $\mathrm{C} 18$ high-performance liquid chromatography (HPLC) column followed by MS-MS multiple reaction monitoring (MRM) with collision induced dissociation. The result showed a characteristic precursor ion at molecular mass 311 which was monitored simultaneously with one of its fragmentation products at mass 293 .

The objective of this study is to determine PE residues in $J$. curcas seed cake, sweet potato, and soil after harvesting by using LC-MS/MS with MRM mode for PE.

\section{MATERIALS AND METHODS}

\section{Seed cake}

Two J. curcas seed cakes were obtained after oil recovery by pressing extraction. The oil content in these cakes was about $1 \mathrm{w} \%$ and $10 \mathrm{w} \%$, respectively. Sweet potato and soil were obtained after harvesting from an experiment on growing sweet potato with Jatropha seed cake as biofertilizer during December, 2008 to March, 2009 at a plantation in Ayutthaya province. The amount of seed cake in each experiment was $1600 \mathrm{~kg} / \mathrm{rai}(10 \mathrm{t} / \mathrm{ha})$. Phorbol-12-myristate-13acetate (TPA) was obtained from sigma chemical Co., Ltd (St. Louis, MO). All other chemical solvents used were of analytical grade.

\section{Determination of phorbol esters content}

Phorbol esters were extracted from $10 \mathrm{~g}$ of $J$. curcas seed cake, dry sweet potato, or soil after harvesting. Extraction used $200 \mathrm{ml}$ of methanol as solvent in Soxhlet extractor running for $4 \mathrm{~h}$. After extraction, methanol was further evaporated by vacuum rotaevaporator until $10 \mathrm{ml}$ of solution was obtained. One portion of solution was used to determine the PE concentration by HPLC-UV. Another portion of solution was analysed by LC-MS/MS MRM mode for confirmation. PE concentration was determined as described $^{6}$. An aliquot was loaded on an HPLC-UV reverse phase C18 LiChrophere 100, $5 \mu \mathrm{m}(250 \times 4 \mathrm{~mm}$ ID. from Merck, Darmstadt, Germany) column. The column was protected with a head column containing the same material. The separation was performed at room temperature $\left(35^{\circ} \mathrm{C}\right)$ and the flow rate was $1 \mathrm{ml} / \mathrm{min}$ using isocratic elution of $1: 1(\mathrm{v} / \mathrm{v})$ deionized water mixed with acrylonitrile as mobile phase. The group of PE peaks was detected at $280 \mathrm{~nm}$ and appeared at 8-12 min of chromatogram. The results were expressed as equivalent to an external standard, phorbol-12-myristate-13-acetate. The detection limit for phorbol esters quantification was $0.03 \mathrm{mg} / \mathrm{g}$.

\section{Confirmation of PE LC conditions}

Chromatographic separation of PE was performed on C18 water Atlantis $(5 \mu \mathrm{m}, 2.7 \times 50 \mathrm{~mm})$. Isocratic program was used with mobile phase, consisted of solvent $(50 \mathrm{~mm}$ ammonium acetate + acetonitrile, $9+1$ ). The flow rate was $0.2 \mathrm{ml} / \mathrm{min}$, the injection volume was $40 \mu \mathrm{l} \mathrm{MS} / \mathrm{MS}$ conditions. MS/MS was performed on a Micromass Quattro Ultima triplequadrupole spectrometer equipped with ESI source. The parameters used for the mass spectrometry under $\mathrm{ESI}^{+}$mode were as follows: capillary voltage $3.00 \mathrm{kV}$, cone voltage $50 \mathrm{~V}$, source block temperature $120^{\circ} \mathrm{C}$, cone gas $52 \mathrm{l} / \mathrm{h}$, desolvation temperature $350^{\circ} \mathrm{C}$, desolvation gas $593 \mathrm{l} / \mathrm{h}$.

\section{RESULTS AND DISCUSSION}

The results of phorbol esters analysis by HPLC-UV in seed cake with low content of oil (1 w\%) and high content of oil (10 w\%) from two chromatograms show a group of peaks indicating low-, and four peaks indicating high-oil content occurring at the retention time from 8-12 min. The concentrations of PE in both chromatograms were calculated by the summation of all area peaks which appeared between 8-12 min and their concentrations were compared with the concentration of TPA used as external standard. The concentrations of PE in seed cake with low and high content 
of oil content were $0.3281 \mathrm{mg} / \mathrm{g}$ and $0.9295 \mathrm{mg} / \mathrm{g}$, respectively. This result indicated that seed cake with low content of oil had less PE concentration than seed cake with high content of oil.

The confirmation of PE by LC-MS/MS with MRM mode of both seed cakes (low and high PE concentration) showed two chromatograms of ionization peaks of PE. Both chromatograms had one peak of ionization that occurred at the same time $(1.54 \mathrm{~min})$, one ionization peak that represented parent molecule with mass 711 ionized to precursor ion with mass 311 and another ionization peak ionized from precursor ion to produce an ion with mass 293. This result could be explained assuming that PE was fragmented by eliminating its ester groups $\left(\mathrm{C}_{13}\right.$ and $\mathrm{C}_{16}$ of Fig. 1) and alcohol group $\left(\mathrm{C}_{20}\right.$ of Fig. 1) to diterpene ester of tigliane type (molecular formula $=\mathrm{C}_{20} \mathrm{H}_{23} \mathrm{O}_{23}$ ) resulting in a precursor molecule with mass 311 . The skeleton was further fragmented by losing $\mathrm{H}_{2} \mathrm{O}$ (molecular mass $=18$ ) to produce ion with mass 293. Hence this characteristic pattern could be used to establish specific detection of PE residue in sweet potato and soil after harvesting as confirmed by the results that follow.

The three samples of sweet potato were analysed by HPLC-UV to give three chromatograms, i.e., PE in control (without seed cake), low, and high PE content in seed cake. No PE peak was detected at the retention time between 8-12 min for sweet potato of control, but PE peaks for sweet potato of seed cake with low and high PE content were observed. The PE content in sweet potato grown by seed cake was $0.1285 \mathrm{mg} / \mathrm{g}$ and $0.1664 \mathrm{mg} / \mathrm{g}$. Chromatograms showed no ionization peaks at the corresponding time (1.54 $\mathrm{min})$ as shown in both ionization peaks of PE in seed cake as observed previously in this study. This suggests that both sweet potato grown by seed cake were not contaminated with toxic PE compounds from seed cake fertilizer.

In the case of soil sample analysis, the result of HPLC-UV from low and high PE content in seed cake was obtained from two chromatograms. The PE confirmation by LC-MS/MS was obtained from two chromatograms of ionization peaks of PE. The result from HPLC-UV chromatogram of both soil samples had a small peak occurring between 8-12 min but after confirmation they did not show the two ionization peaks occurring at $1.54 \mathrm{~min}$, indicating that no $\mathrm{PE}$ was left in the soil after harvesting.

\section{CONCLUSIONS}

It can be concluded that LC-MS/MS with multiple reaction monitoring mode can be used to confirm the presence of PE residues in sweet potato and soil after harvesting. In addition, Jatropha seed cake with low and high PE content can be applied for biofertilizer with environmental friendly and safety.

Acknowledgements: This study was supported by the Higher Education Research Promotion and National Research University Project of Thailand, Office of the Higher Education Commission. We also would like to thank the Centre of Excellence Oil Palm Kasetsart University and King's Royally Initiated Laem Phak Bia Environmental Research and Development Project for partial supporting this study.

\section{REFERENCES}

1. Saetae D, Suntorusuk W (2010) Variation of phorbol esters contents in Jatropha curcas from different provinces in Thailand and the application of its seed cake for starter broiler diets. Am Euras J Agric Environ Sci 8, 497-501.

2. Xiao J, Zhang H (2011) Evaluation of detoxification methods in toxic and antinutritional composition and nutritional quality of proteins in Jatropha curcas meal. J Agr Food Chem 59, 4040-4.

3. Haas W, Mittelbach (2000) Detoxification experiments with the seed oil from Jatropha curcas L. Ind Crop Prod 12, 111-8.

4. Vogg G, Achatz S, Kettrup A, Saudermuun H (1999) Fast, sensitive and selective liquid chromatographictandem mass spectrometric determination of tumorpromoting diterpene esters. J Chrom A 855, 563-73.

5. Wink M, Grimm C, Koschmieder C, Sporer F, Beargeot O (2000) Sequestration of phorbol esters by the aposematically coloured bug pachycoris blugii (Heteroptera: scutelleridue) feeding on Jatropha curcas (Euphorbiaceae). Chemoecology 10, 179-84.

6. Punsuvon V, Nokkaew R, Vaithanomsat P (2008) Eliminated phorbol esters in seed oil and press cake of Jatropha curcas L. Proceedings in Pure and Applied Chemistry International Conference, pp 202-207. 